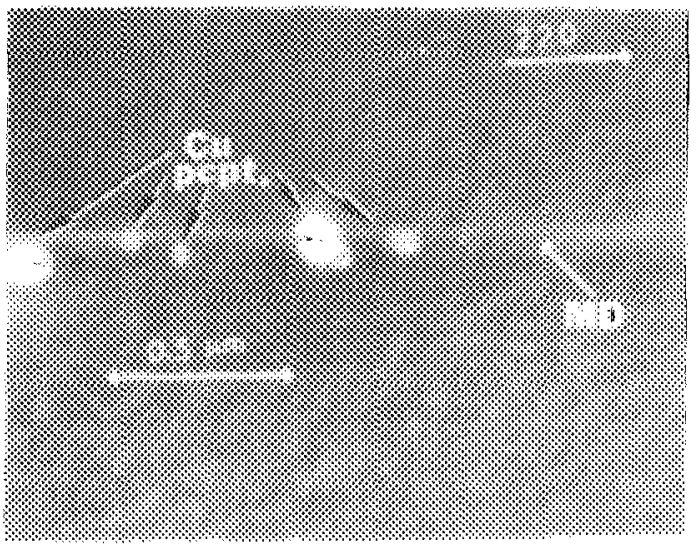

FIG. 4. Beveled TEM of Cu precipitates at a misfit dislocation MD.

misfit dislocations is clearly presented by the strain fields produced by the $\mathrm{Cu}$ precipitates as indicated on the micrograph in Fig. 4.

In summary, it has been demonstrated that interfacial misfit dislocations introduced during Ge-doped Si epitaxy can be used as extrinsic gettering sites. The dislocations, at densities from $10^{6}$ to $10^{8} \mathrm{~cm}^{-2}$, have separations on the order of $1-10 \mu \mathrm{m}$ and do not appear to interact such that threading dislocations result. Single, graded, and multistep layers have been grown to illustrate the defect density control possibilities and the flexibility of the procedure. Both $\mathrm{Au}$ and $\mathrm{Cu}$ diffusion from 200 to $300 \AA$ A thick evaporated surface films have been examined with SIMS and TEM. The relative gettering efficiency of high and low misfit dislocation density interfaces has been demonstrated for these metallic impurities to establish extrinsic gettering with interfacial disloca- tions as a viable alternative to conventional intrinsic and backside gettering.

The authors would like to acknowledge C. W. Pearce for discussions in the early stages of this work, as well as the financial support of the Semiconductor Research Corporation. The authors are also grateful to the Government of Sudan which supports Mr. Ali Salih.
'P. J. Ward, J. Electrochem. Soc. 129, 2573 (1982).

${ }^{2}$ P. F. Schmidt and J. Pearce, J. Electrochem. Soc. 128, 630 (1981).

'E. J. Mets, J. Electrochem. Soc. 112, 420 (1965).

${ }^{4}$ H. J. Geipel and W. K. Tice, Appl. Phys. Lett, 30, 325 (1977).

'G. A. Rozgonyi, P. M. Petroff, and M. H. Read, J. Electrochem. Soc. 122, No. 12,1725 (1975).

'S. M. Hu, Appl. Phys. Lett. 31, 53 (1977).

${ }^{7}$ T. Y. Tan, E. E. Gardner, and W. K. Tice, Appl. Phys. Lett. 30, 175 (1977). ${ }^{8}$ G. A. Rozgonyi and C. W. Pearce, Appl. Phys. Lett. 32, 747 (1978).

${ }^{9} J$. O. Borland, M. Kuo, J. Shibley, B. Roberts, R. Schindler, and T. Dalrymple, in Semiconductor Processing, ASTM STP 850, edited by D. Gupta (American Society for Testing and Materials, Philadelphia, PA, 1984), p. 49.

${ }^{10} \mathrm{C}$. W. Pearce and G. A. Rozgonyi, in VLSI Science and Technology/ 1982, edited by C. J. Dell'Oca and W. M. Bullis (The Electrochemical Society, Pennington, NJ, 1982), p. 53.

"VLSI Science and Technology/1982, edited by C. J. Dell'Oca and W. M. Bullis (The Electrochemical Society, Pennington, NJ, 1982), pp. 5-59.

${ }^{12}$ W. Maszara, C. Carter, and G. A. Rozgonyi, VLSI Science and Technology, edited by K. Bean and G. A. Rozgonyi (The Electrochemical Society, Pennington, NJ, 1984), p. 36.

${ }^{13}$ W. Dyson, L. Hollwig, J. Moody, and J. Rossi, in Defects in Silicon, edited by W. Murray Bullis and L. C. Kimerling (The Electrochemical Society, Pennington, NJ, 1983), p. 246.

\title{
Hydrogen localization near boron in sllicon
}

\author{
J. I. Pankove, P. J. Zanzucchi, and C. W. Magee \\ RCA Laboratories, Princeton, New Jersey 08540
}

G. Lucovsky

North Carolina State University, Raleigh, North Carolina 27650

(Received 27 September 1984; accepted for publication 28 November 1984)

Several models of boron neutralized by atomic hydrogen in silicon were tested by secondary ion mass spectrometry and infrared spectrometry. The hydrogen concentration is comparable to that of boron. Boron neutralization appears as a drop in free-carrier absorption and as an increase in resistivity. A new infrared vibrational mode attributed to $\langle 111\rangle$ vibrations of $\mathrm{H}$ tied to $\mathrm{Si}$ appears at $1875 \mathrm{~cm}^{-1}$.

Shallow acceptors in crystalline silicon have been neutralized in several different experiments. ${ }^{3-5}$ Although there is general agreement that after the treatment boron no longer acts as an acceptor, there has been no agreement on the specific model that describes the substitutional boron-hydrogen complex in silicon. Pankove et al. ' introduced atomic hydro- gen $\left(\mathbf{H}_{1}\right)$ into $\mathbf{B}$-doped $\mathrm{Si}$ at $\sim 125^{\circ} \mathrm{C}$ and found a substantial increase in resistivity near the surface. Sah et al..$^{2.4}$ and Gale et al. ${ }^{3}$ used avalanche breakdown or electron bombardment of a metal-oxide-semiconductor structure to drive $\mathrm{H}_{1}$ from $\mathrm{SiO}_{2}$ into the B-doped crystal and found a decrease in capacitance due to the widening of the depletion layer resulting 
$\mathrm{Si}=\|_{\mathrm{B}}^{\mathrm{Si}} \mathrm{H}=\mathrm{Si}$
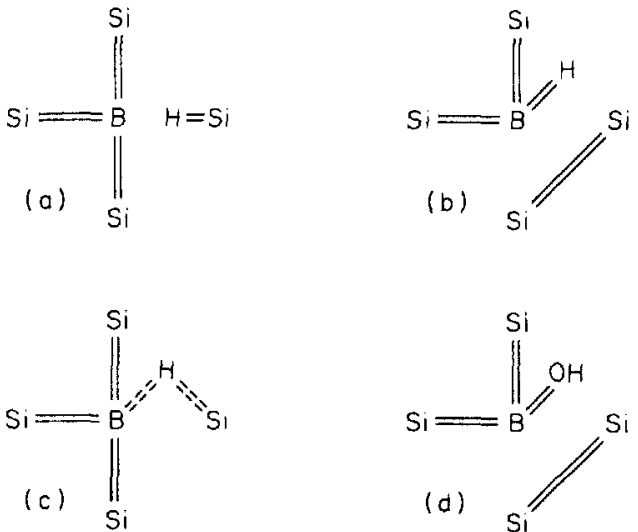

FIG. 1. Models of neutralized substitutional boron in silicon. Hydrogen bonded to (a) Si, (b) B, (c) "bridging bond", (d) OH bonded to B

from the increased resistivity in the treated region. Hansen $e t$ $a l{ }^{5}$ have tested Schottky diodes on $p$-type Si treated in a plasma of water vapor and found also a decreased capacitance for the same reason.

These various experiments have spawned four models that could explain the neutralization of boron. These four models are shown in Fig. 1. According to our model' [Fig. 1(a)] $H_{1}$ is tied to one of the four silicon atoms surrounding the substitutional boron atom, thus leaving all the valence bonds satisfied. Sah et al. ${ }^{4}$ proposed that $\mathrm{H}_{1}$ is tied to $\mathrm{B}$ thus requiring the reconstruction of dangling bonds between adjacent Si atoms [Fig. 1(b)]. An alternative model ${ }^{6}$ is a bridging bond between $\mathrm{B}$ and $\mathrm{Si}$ [Fig. 1(c)]. The model that Hansen et al. ${ }^{5}$ proposed has a hydroxyl group attached to boron [Fig. 1(d)].

In order to distinguish among these models we have made two types of measurements. In the first one, we examined the concentration profiles of boron, hydrogen, and oxygen in a $\mathrm{B}$-implanted sample $\left(10^{16} \mathrm{~B} / \mathrm{cm}^{2}\right.$ at $\left.100 \mathrm{keV}\right)$ that had been annealed at $1100^{\circ} \mathrm{C}$ for $16 \mathrm{~h}$ and then hydrogenated at $125^{\circ} \mathrm{C}$ for $156 \mathrm{~h}$ by exposure to $\mathrm{H}_{1}$ generated by an $\mathrm{rf}$ glow discharge in 0.2 Torr of hydrogen. The purpose of this measurement was to check if oxygen might have either leaked into our system or been dislodged from the quartz walls in sufficient quantity to generate the hydroxyl of Fig. 1(d). The result of secondary ion mass spectrometry (SIMS) is shown in Fig. 2. It is evident that there is enough hydrogen to neutralize $80 \%$ of the boron to a depth of $-2 \mu \mathrm{m}$, but the oxygen concentration is two orders of magnitude lower. Hence the hydroxyl-boron complex, if present, is not a significant component in our specimen. The inset of Fig. 2 shows the electrical neutralization of boron as an increase in spreading resistance near the surface.

The second measurement, the infrared absorption spectrum, was aimed at determining the nature of the $\mathrm{H}$ bonding. specifically whether the $\mathrm{H}$ atom was bonded to $\mathrm{B}$ or to $\mathrm{Si}$ or to both. The measurement was made by using a multiple internal reflection prism ${ }^{7}$ of $\mathrm{Si}$ which initially was B doped on one surface by $B$ ion implantation $\left(10^{15}\right.$ ions $/ \mathrm{cm}^{2}$ at 100 $\mathrm{keV} /$ and then annealed at $1100^{\circ} \mathrm{C}$ for $16 \mathrm{~h}$. This surface was then hydrogenated for $65 \mathrm{~h}$ at $120^{\circ} \mathrm{C}$. The IR spectrum measured with a Fourier transform spectrometer is shown in Fig. 3. The spectrum exhibits two changes with respect to one measured after implantation and annealing, but prior to

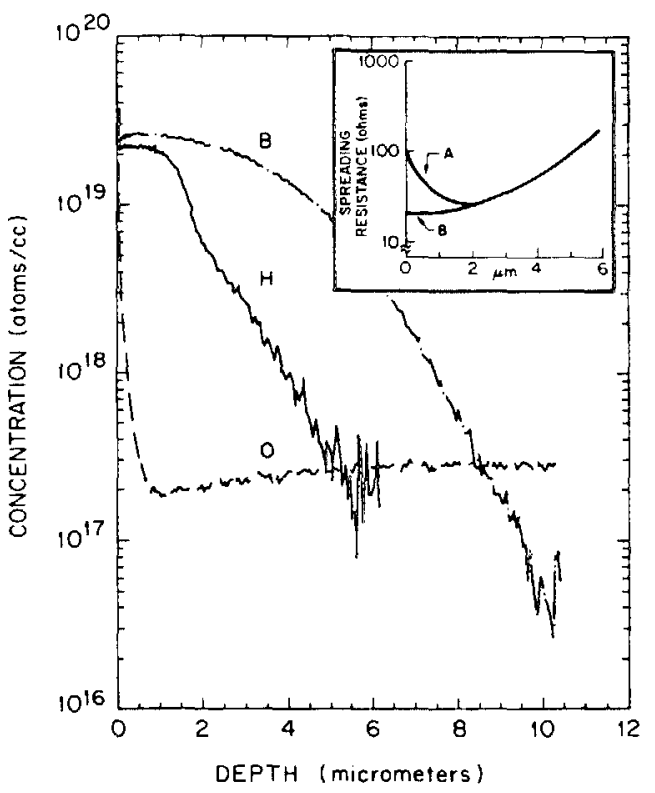

FIG. 2. SIMS concentration profiles of $\mathrm{B}, \mathrm{H}$, and $\mathrm{O}$ in silicon. The inset shows the spreading resistance of this sample before $(\mathbf{B})$ and after $(\mathbf{A})$ hydrogenation. The hole concentration at the surface is $2.0 \times 10^{19} \mathrm{~cm}^{3}$ before and $1.4 \times 10^{18} \mathrm{~cm}^{-3}$ after hydrogenation.

hydrogenation not shown in Fig. 3. First there is a decrease in the free-carrier absorption that is consistent with the increase in electrical resistivity following hydrogenation. Second there is a relatively sharp absorption band at $1875 \mathrm{~cm}^{-1}$. The frequency of this mode is in the range of $\mathrm{H}$ atom bondstretching vibrations. In order to develop a structural model for the local bonding chemistry of the $\mathrm{H}$ atom, we first indicate the range of $\mathbf{H}$ atom bond-stretching frequencies so far measured for configurations involving $\mathrm{B}$ and $\mathrm{Si}$ atom neighbors.

The bonding of $\mathbf{H}$ atoms in amorphous $\mathrm{Si}$ has received considerable attention with two recent review articles summarizing the experimental results and their interpretation in terms of local bonding groups. ${ }^{8,9}$ The result that is pertinent here concerns the frequency of monohydride or $\mathrm{Si}-\mathrm{H}$ vibrations. Two modes have been identified, one at approximately $2000 \mathrm{~cm}^{-1}$ and a second at about $2100 \mathrm{~cm}^{-1}$. There have also been studies of $\mathrm{H}$ ion implantation in to crystalline $\mathrm{Si}$ at low temperature with stretching frequencies ranging from 1885 to approximately $2200 \mathrm{~cm}^{-1}$, $^{10,11}$ but the low-frequency vibration disappears at $200 \mathrm{~K}$. Tsai ${ }^{12}$ has studied the IR

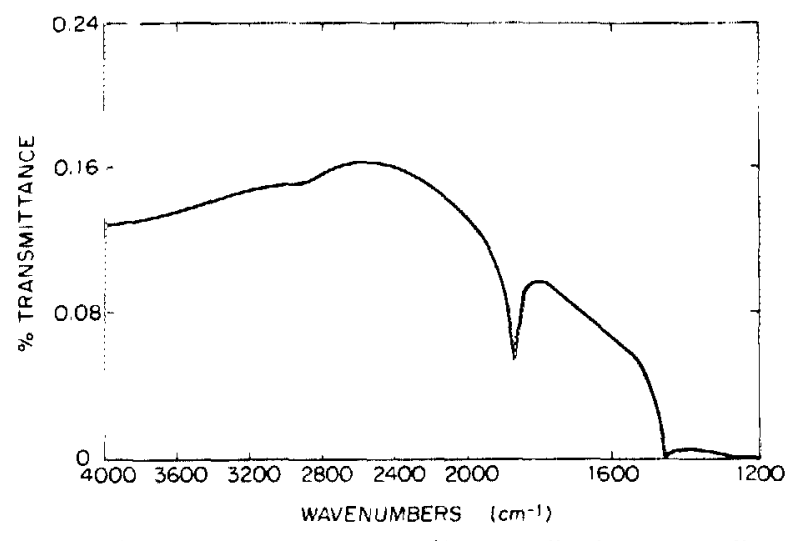

FIG. 3. IR transmission spectrum of $\mathbf{H}$ neutralized boron in silicon. 

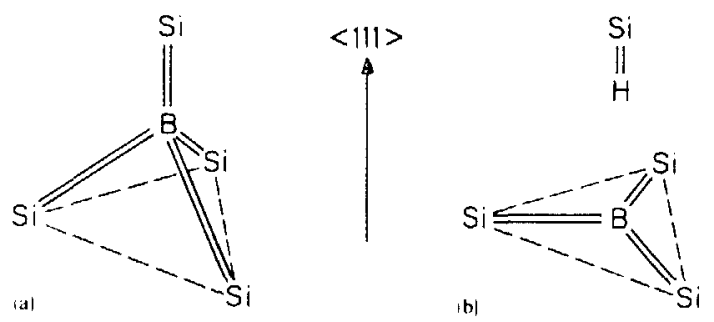

FIG. 4. Model of substitutional boron in silicon before (a) and after (b) $H$ neutralization. In (a), a hole (not shown) in the vicinity of the boron provides charge neutrality.

spectra of $a-\mathrm{Si}: \mathrm{B}: \mathrm{H}$ alloys and has identified the vibrations associated with $\mathrm{B}-\mathrm{H}$ bonding groups.

Terminal $\mathrm{H}$ bonding configurations $(\mathrm{B}-\mathrm{H})$ give a relatively sharp feature at $2560 \mathrm{~cm}^{-1}$ whereas bridging $\mathrm{H}$ atoms (B-H-B) give a relatively broad feature centered at about $1985 \mathrm{~cm}^{-1}$. These assignments are based on the interpretation of the IR spectra of diborane. There are no measurements to date that have identified other $\mathrm{H}$ atom bridging configurations with $\mathrm{Si}$ such as $\mathrm{Si}-\mathrm{H}-\mathrm{Si}$ or $\mathrm{Si}-\mathrm{H}-\mathrm{B}$. Nevertheless, based on comparisons with the results in Ref. 12, we would expect these features to be relatively broad with linewidths greater than $100 \mathrm{~cm}^{-1}$.

Based on the observations mentioned above, we conclude that the vibration at $1875 \mathrm{~cm}^{-1}$ is a $\mathrm{Si}-\mathrm{H}$ vibration. This follows from (1) the sharpness of the feature, linewidth less than $50 \mathrm{~cm}^{-1}$, and (2) the frequency relative to the range of measured $\mathrm{B}-\mathrm{H}$ and $\mathrm{Si}-\mathrm{H}$ frequencies. Figure 4 presents a model for the local bonding configuration involving the $\mathrm{H}$ atom. This model accounts for the frequency of vibration as well as the change in electrical properties. The $\mathrm{H}$ atom is inserted between the $\mathrm{B}$ atom and one of its four $\mathrm{Si}$ atom neighbors and bonds to the $\mathrm{Si}$ atom generating a $\mathrm{Si}-\mathrm{H}$ group. The $\mathrm{B}$ atom then relaxes toward the plane of its three $\mathrm{Si}$ neighbors. This particular type of "alloy atom" center satisfies all of the valence bonding requirements of the $\mathrm{H}$ atom, the $\mathrm{B}$ atom, and the four $\mathrm{Si}$ atoms. Neither the $\mathrm{Si}-\mathrm{H}$ group nor the threefold-coordinated $B$ atom is electronically active as a donor or acceptor, hence the drop in electrical conductivity and free-carrier absorption. The electronic configurations do not favor the formation of a three-center $\mathrm{Si}-\mathrm{H}-\mathrm{B}$ bond of the same general type as in the $\mathrm{B}-\mathrm{H}-\mathrm{B}$ bond in diborane. The stretching frequency of the $\mathrm{Si}-\mathrm{H}$ vibration is at the low end of the reported range of $\mathrm{Si}-\mathrm{H}$ bond-stretching frequencies. This can be explained in two ways: (1) the effective force constant of the $\mathrm{Si}-\mathrm{H}$ vibration is reduced by a three-body force involving the $\mathrm{Si}-\mathrm{H}-\mathrm{B}$ triad of atoms; and (2) the frequency of vibration can be lowered due to local field effects associated with the dielectric cavity in the crys- talline Si host material. ${ }^{y}$ The first explanation involves a three-body force of the general form $k_{r R}$, where $r$ is the $\mathrm{Si}-\mathrm{H}$ bond length and $R$ is the distance between the $\mathrm{H}$ and $\mathrm{B}$ atoms. For $k_{r R}$ positive, this type of force will always contribute a negative term to the potential energy; i.e., the contribution is given by $A k_{r R} \Delta r \Delta R$, where $A$ is a constant and $\Delta r$ and $\Delta R$ are changes in the two interatomic distances. For the bond-stretching motion we are considering, $\Delta r$ and $\Delta R$ are always opposite in sign. This type of force is qualitatively similar to the force that couples intra- and interchain motions in trigonal Se and $\mathrm{Te}$, and has a similar effect in reducing the frequency of a symmetric bond-stretching motion. ${ }^{13}$

The second model, based on local field effects, is discussed in Ref. 9. In either case, the magnitude of a frequency shift from about 2000 to $1875 \mathrm{~cm}^{-1}$ is consistent with the model. For the force constant model the $k_{r R}$ force would have to be about 0.14 the size of the $\mathrm{Si}-\mathrm{H}$ two-body force, and for the second case the size of the dielectric cavity would have to be about the size of a monovacancy.

Using Raman scattering, Steigmeier of RCA Zurich has found in one of our samples a weak structure at 1875 $\mathrm{cm}^{-1}$. This finding, which implies a lack of inversion symmetry, is consistent with our $\mathrm{Si}-\mathrm{H}$ model.

In summary, we have designed experiments to test the suitability of several models that might explain the neutralization of boron by hydrogen as evidenced by increased resistivity and decreased free-carrier absorption. We find that oxygen or $\mathrm{OH}$ is not a significant component, and the vibrational spectrum indicates that $\mathrm{H}$ is tied to one $\mathrm{Si}$, and $\mathrm{B}$ to three Si.

We are grateful to R. O. Wance for the spreading resistance measurements. One of the authors $(G L)$ is pleased to acknowledge partial support of this research under ONR contract N00014-79-C-0133.

'J. I. Pankove, D. E. Carlson, J. E. Berkeyheiser, and R. O. Wance, Phys. Rev. Lett. 51, 2224(1983).

${ }^{2}$ C. T. Sah, J. Y. C. Sun, and J. J. Tzou, Appl. Phys. Lett. 43, 204 (1983). ${ }^{3}$ R. Gale, F. J. Feigl, C. W. Magee, and D. R. Young, J. Appl. Phys, 54, $6938(1983)$.

${ }^{4}$ C. T. Sah, J. Y. C. Sun, and J. J. Tzou, J. Appl. Phys. 55, 1525 (1984).

${ }^{5}$ W. L. Hansen. S. J. Pearton. and E. E. Haller, Appl. Phys. Lett, 44, 606 (1984)

"C. T. Sah (personal communication).

'N. V. Harrick, Internal Reflection Spectroscopy (Wiley, NY, 1967).

${ }^{8}$ G. Lucovsky and W. B. Pollard, in Topics in Applied Physics, Vol. 56, The Physics of Hydrogenated Amorphous Silicon II, edited by J. D. Joannopoulos and G. Lucovsky (Springer, Berlin, 1984), p. 301.

"M. Cardona, Phys. Status Solidi B 118, 463 (1983).

"'H. J. Stein. Phys. Rev, Lett. 43, 1030 (1979).

"H. J. Stein and P. S. Peercy, Phys. Rev. B 22, 6233 (1980).

${ }^{12}$ C. C. Tsai, Phys. Rev. B 19, 2041 (1979).

'"R. M. Martin, G. Lucovsky, and K. Helliwell, Phys. Rev. B 13, 1983 (1976). 